\title{
Electron microscopic observations and speculations on Australia antigen
}

\author{
JUNE D. AlmeidA
}

Royal Postgraduate Medical School, Hammersmith, London, W.12

\begin{abstract}
Summary
The use of the electron microscope has simplified methods of detection of Australia antigen in carriers of serum hepatitis, in patients suffering from the disease and those with persistent hepatitis.

Basic studies on the nature and properties of Australia antigen, using the electron microscope, are described.
\end{abstract}

THE correlation between the Australia antigen and serum hepatitis is now so good (Le Bouvier \& McCollum, 1970) that a study of the one is automatically a study of the other. This paper deals with one aspect of these studies, the morphology as seen by the electron microscope technique of negative staining. It will consider the practical use to which this morphological information can be put and will go on to speculate on the insight that such studies may give on the nature of the virus of serum hepatitis.

Although the Australia antigen was discovered in the early 1960s it was not until 1968 that it was first examined by negative staining in the electron microscope. This was done from gradient purified preparations and revealed mainly a small spherical component approximately $200 \AA$ in diameter (Bayer, Blumberg \& Werner, 1968). This appearance was quickly confirmed by other workers both in purified preparations and also in immune aggregates (Prince, 1968; Millman et al., 1969). Also in 1969, Almeida et al., showed that by simple centrifugation it was possible to visualize the particles of the Australia antigen within a short time of receiving a serum specimen. These negatively stained preparations of the antigen revealed that it exists in two main forms, the spherical component previously mentioned and a tubular one again having a diameter of $200 \AA$ but having variable lengths up to several $1000 \AA$ units (Fig. 1). No regular substructure can be visualized on the spheres and indeed in overall diameter they show an irregularity of size ranging from $160 \AA$ to $250 \AA$. The tubular component, on the other hand, revealed a cross striation with a periodicity of $30 \AA$ in well oriented examples (Fig. 2). The proof that these structures do indeed identify with the Australia antigen demonstrated by other techniques is that precipitin lines cut out from

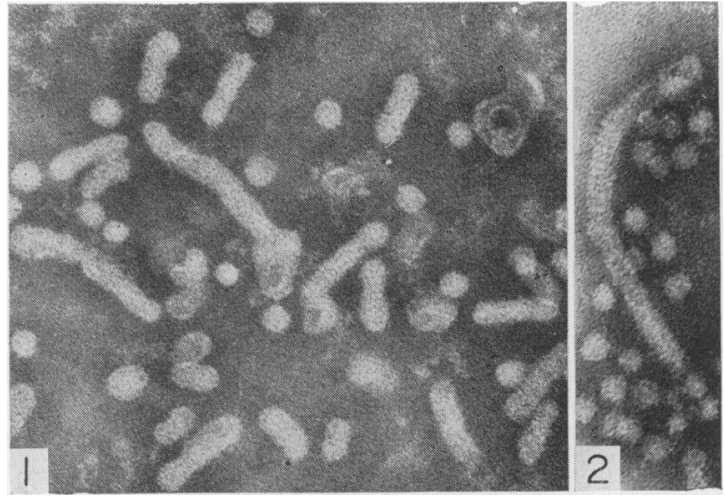

FIg. 1. A typical field of $\mathbf{A u}-\mathbf{A g}$ as seen by negative staining. Predominantly the micrograph shows the $200 \AA$ diameter spheres and tubules associated with the antigen. However, in addition, there is also a Dane particle showing the internal shell in the top right-hand corner. $\times 125,000$.

FIg. 2. The tubule shown in this micrograph exhibits along its length the rather vague $30 \AA$ periodicity which seems to be the only regular substructure associated with the Au-Ag. $\times 150,000$.

agar gel are built up from the described particles and in addition specific antisera can be added to preparations containing the antigen and specific complexing observed (Almeida et al., 1969).

Because of the overall simplicity of visualizing these distinctive structures of the Australia antigen by negative staining the electron microscope is now used extensively for this purpose and it appears to be useful on two separate levels. The first level is completely practical and entails the use of the microscope to diagnose the presence of the antigen. The second use is the more basic one of identifying the causative agent of serum hepatitis and, in a disease where there is as yet no biological means of recognizing the presence of the virus, is the most available means of characterizing it. This paper will now deal with these two aspects separately starting first with the practical one.

Practical uses of the electron microscope in dealing with serum hepatitis

As has already been stated simple centrifugation of a serum specimen followed by negative staining 
of the pellet so obtained allows visualization of the antigen (Almeida et al., 1969). The time-lapse between receiving a specimen and examination in the microscope is a little over $2 \mathrm{hr}$, a time that compares favourably with other methods of examination. In addition, in our hands, electron microscope examination has been the most sensitive means of detecting the presence of the antigen. Also, in addition to sensitivity, the distinctive structures visualized and the permanent micrograph record mean that it is possible to reach a definite diagnosis with certainty and in some instances, e.g. a potential patient in a haemodialysis unit: it is very important that this can be done.

This then is probably the most frequently employed use of the electron microscope in the serum hepatitis field, simple diagnosis of the presence of Australia antigen (Au-Ag). But in addition to showing the presence of the antigen it was realized that different patterns of distribution could be seen on the microscope grid. Some specimens contain randomly distributed antigen but in other cases it appears clumped, with all the appearances of an antigen-antibody complex, although no antiserum had been added. This effect has been investigated and it now appears that the type of distribution of the antigen can be associated with different states. These are:

\section{(1) Carriers of serum hepatitis}

These are people who have been recognized by the blood transfusion service as having transmitted serum hepatitis but on investigation are found to have normal liver function. The sera from four such carriers have now been examined and in each case the antigen was found to be randomly distributed (Fig. 3).

\section{(2) Patients suffering from serum hepatitis}

The haemodialysis unit at the Hammersmith Hospital experienced an outbreak of serum hepatitis from October 1969 to February 1970 and during this time regular specimens were taken from all patients and staff on the unit and stored at $-20^{\circ} \mathrm{C}$. This allowed us to follow in serial fashion any patients or staff members who contracted the disease and in one case to examine serum obtained at a point before the illness had begun. These findings will be discussed in greater degree elsewhere (Trowell et al., 1971) but in summary it can be stated that in three cases followed during the course of an attack of serum hepatitis the $\mathrm{Au}-\mathrm{Ag}$ changed from an initially random distribution to an aggregated one and finally these aggregates disappeared from the serum. In the one case where serum was available before the onset of the disease the antigen was found to have been present in the routinely

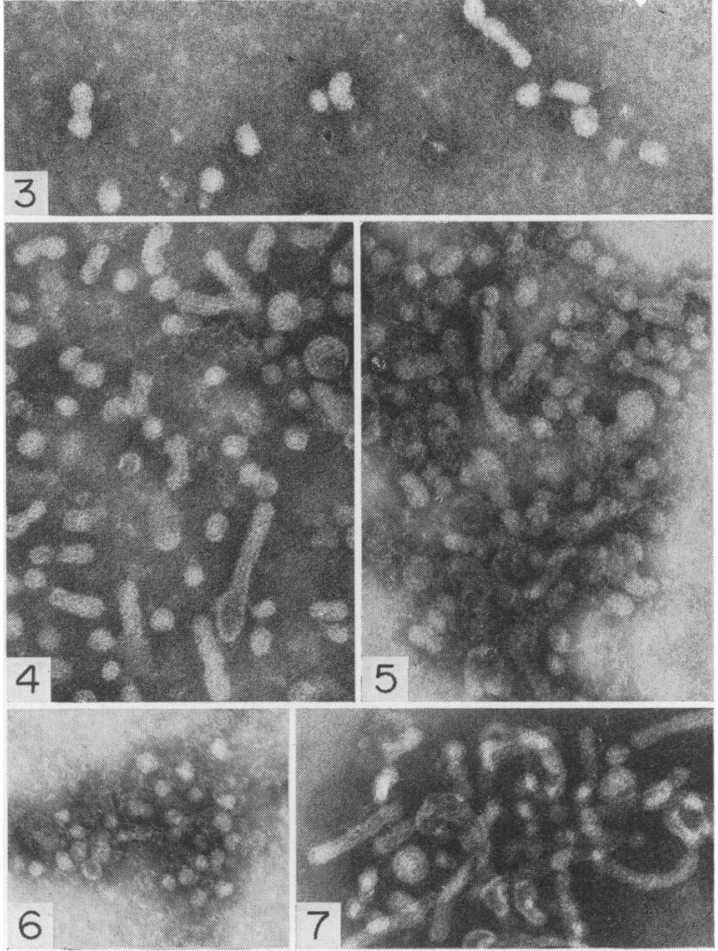

Fig. 3. When sera from known carriers of serum hepatitis were examined in the electron microscope the antigen appeared as here, random and unaggregated. $\times 100,000$.

FIGs. 4-6. The change in distribution that appeared in a patient's serum during the course of an attack of serum hepatitis. FIG. 4. This specimen was obtained within a few days of the onset of the disease and at this time the antigen is unaggregated. $\times 100,000$. Fig. 5. This micrograph was obtained a week later than Fig. 4 and now the particles of the $\mathrm{Au}-\mathrm{Ag}$ are obscured by the presence of antibody molecules and their distribution is no longer random but aggregated in the centre of the micrograph. $\times 100,000$. FIG. 6 . At this point the patient was recovering from the illness and it was only with difficulty that small aggregates such as the one shown here could be found. $\times 100,000$.

FIG. 7. This micrograph was obtained from one of asmall number of patients examined who had persistent viral hepatitis. All of those who were Au-Ag positive gave a similar picture of aggregated antigen such as the one shown here. In addition, it was also observed that in these persistent cases the tubular or filamentous component predominated. $\times 100,000$.

stored specimen a week before the disease became manifest. To sum up this section it appears from our studies that in the normal course of serum hepatitis there is first a stage of non-complexed antigen leading to one where the antigen appears in aggregates which have the appearance of antigenantibody complexes and that these are finally cleared from the system (Figs. 4-6). 


\section{(3) Persistent viral hepatitis}

It has been possible to examine the serum from a small number of patients with persistent viral hepatitis and, in those found positive for the antigen, electron microscope examination has revealed the presence of the complexed form of the Australia antigen for periods of up to one year. (Fig. 7)

The relevance of these different patterns of distribution is not yet established although there is corroborative evidence from other techniques substantiating the presence of immune complexes in the sera of patients with serum hepatitis (Shulman \& Barker, 1969). This has led us to suggest (Almeida \& Waterson, 1969) that serum hepatitis may have some aspects in common with serum sickness and that the effect of the Au-Ag may indeed be through its activity as an antigen. This speculation, however, belongs rather in the section dealing with basic uses of the microscope than in that dealing with practical aspects.

To conclude this section on the practical use of the electron microscope for the study of Australia antigen, it can be stated that the negative staining technique allows the recognition not just of the Australia antigen but also gives a possible insight into the status of the patient depending on the distribution of the antigen.

\section{Basic studies on serum hepatitis using the electron microscope}

The last section attempted to show that visualization of the $\mathrm{Au}-\mathrm{Ag}$ can be of considerable diagnostic help but it must be recognized that the exact nature of the antigen is still far from certain.

Numerous attempts have been made to culture it but all of them have been unsuccessful. In addition Gerin et al. (1969) carried out biochemical assays on gradient-purified Australia antigen and were unable to detect the presence of nucleic acid. These two pieces of information, lack of biological activity and absence of nucleic acid, make it very unlikely that the $\mathrm{Au}-\mathrm{Ag}$ is itself a virus. In addition, the lack of biological activity limits severely the studies that can be carried out on the antigen. This in turn means that the electron microscope is, at the present, the most fruitful approach to the problem of the $\mathrm{Au}-\mathrm{Ag}$ and serum hepatitis and we shall now consider the various morphological findings that have been made.

The negatively stained appearance of the $\mathrm{Au}-\mathrm{Ag}$ has already been described, but in addition to the approximately $200 \AA$ spheres and tubules, Dane, Cameron \& Biggs, (1970) described a third type of particle present in Australia antigen preparations. This particle has a double-shelled structure, the outer shell having a diameter of $420 \AA$ and the inner, one of $280 \AA$ (Fig. 8). In contrast to the smaller, approximately $200 \AA$ particle, the $420 \AA$ structure is more or less constant in size. The situation was further confounded when typical virus-like particles of $270 \AA$ diameter (Fig. 9) were found in homogenates of two post-mortem livers from patients dying in the acute stage of serum hepatitis (Almeida et al., 1970).

All of these results have been obtained by the negative staining technique but other workers have used the thin-sectioning technique on liver biopsy material. Nowoslawski et al. in 1970 described $200 \AA$ particles in the nuclei of hepatic cells in $\vec{\circ}$ biopsy material from patients positive for the Australia antigen. Shortly after, Nelson, Barker \& Danovitch (1970) although finding fewer infected nuclei confirmed this finding and showed $200 \AA$ particles in liver biopsy material. These intranuclear particles have a regular diameter and have the appearance acceptable for viruses as seen by the thin-sectioning technique.

We have then four different morphological groups: the spheres and tubules of the Australia antigen (Fig. 1); the particles described by Dane et al. (1970) which we shall describe as Dane particles (Fig. 8); the $200 \AA$ particles seen by thin sectioning; and the $270 \AA$ particles present in liver homogenates (Fig. 9). This completes the factual informas tion yielded by the electron microscope in serup hepatitis but it seems worthwhile to speculate on the possible nature and inter-relationship of thes

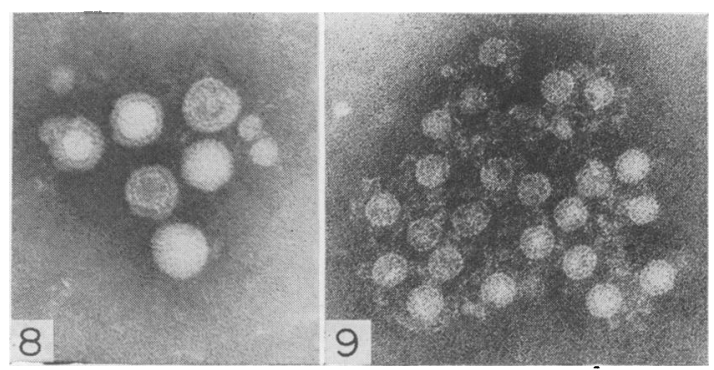

Fig. 8. A group of the particles first described by Dane et al. (1970). Unlike the Au-Ag these particles have a relatively constant diameter of $420 \AA$ and a regular inner component of $280 \AA$. Two of the particles shown here have been penetrated by stain to reveal the inner component. This internal component should be compared with the particles recovered from liver homogenates shown in Fig. 9. In addition, this micrograph shows two spherical particles of $\mathrm{Au}-\mathrm{Ag}$ linked to the outer surface of the Dane particles suggesting that there is antigenic identity between these two structures. $\times 150,000$.

Fig. 9. A group of typically virus-like particles present in the liver homogenate of a patient dying in the acute phase of serum hepatitis. These particles show a strong resemblance to established small cubic viruses such as the rhinoviruses. It is suggested in the text that these particles could well identify with the internal component of the Dane particles shown in Fig. 8. $\times 150,000$. 
four distinct groups. At first sight it might appear that a $200 \AA$ intranuclear particle in thin-sectioned material correlates well with the $200 \AA$ particle of Australia antigen as seen by negative staining, but this is not true. The Au-Ag particles are distinctly pleomorphic (Almeida et al., 1969) while the intranuclear particles have a reasonably constant diameter of $200 \AA$. In addition a particle of $200 \AA$ in thin section would be expected to have a diameter between 270 and $300 \AA$ in negatively stained preparations, as considerable shrinkage occurs during processing for thin sectioning. This leads to a consideration of whether the $200 \AA$ intranuclear particle by thin sectioning does not correlate with the $270 \AA$ particle seen by negative staining in liver homogenates. Turning now to the Dane particle the inner component of this has an established size of $280 \AA$ and is described as having a more delicate appearance than that of the Australia antigen. This again could correlate with the $270 \AA$ liver homogenate particles. Antibody to the Australia antigen cross links with the outer shell of the Dane particle and this would mean we are dealing with the same protein (Fig. 8). This speculation would then leave us with the suggestion that the Australia antigen is excess protein of the same type as the outer covering of the Dane particle while the particles described in liver represent the internal component of the same particle. This speculation is strengthened by the fact that Cossart \& Field (1970) pointed out that there was a structural similarity between the negatively stained appearance of the Australia antigen and that of the protein component of some plant viruses (Bancroft, Mills \& Markham, 1967; Bancroft, Bracker \& Wagner, 1969; Bancroft, Hiebert \& Bracker, 1969). We are left then with a whole series of speculations based on the multiplicity of electron microscope findings that can be summarized as follows: The most likely candidate for the virus of serum hepatitis is the Dane particle which could have as its internal component the virus-like $270 \AA$ particles seen in liver homogenates while these in turn could identify with the $200 \AA$ particles seen intranuclearly in thin-section preparations. On the basis of an analogous situation in plant virology there is good reason to suspect that the $\mathrm{Au}-\mathrm{Ag}$ represents viral protein and has its use in diagnosis of serum hepatitis because it has antigenic identity with the outer layer of the Dane particle. However, as must obviously be clear the non-biological information obtained from the electron microscope can never stand by itself in characterising a virus and until some method is obtained of handling the serum hepatitis virus in vitro the electron microscope remains as a ready and simple means of visualizing the antigen and perhaps offering a suggestion as to the course future research could take.

\section{Acknowledgments}

The author would like to thank Mrs G. Carnegie for skilled technical assistance and Dr J. M. Trowell, Dr G. Neale, Dr H. Whittle and Dr N. Davidson for clinical liaison, also Professor A. P. Waterson for his invaluable discussions on this subject. The author is supported by a grant from the Medical Research Council.

\section{References}

Almeida, J.D. \& Waterson, A.P. (1969) Immune complexes in hepatitis. Lancet, ii, 983.

Almeida, J.D., Waterson, A.P., Trowell, J.M. \& Neale, G. (1970) The finding of virus-like particles in two Australia-antigen-positive human livers. Microbios, 6, 145.

Almeida, J.D., Zuckerman, A.J., Taylor, P.E. \& WaterSON, A.P. (1969) Immune electron microscopy of the Australia-SH (serum hepatitis) antigen. Microbios, 2, 117.

Bancroft, J.B., Mills, G.T. \& Markham, R. (1967) A study of the self-assembly process in a small spherical virus. Formation of organised structures from protein subunits in vitro. Virology, 31, 354.

Bancroft, J.B., Bracker, C.E. \& Wagner, G.W. (1969) Structures derived from cowpea chlorotic mottle and brome mosaic virus protein. Virology, 38, 324.

Bancroft, J.B., Hiebert, E. \& Bracker, C.E. (1969) The effects of various polyanions on shell formation of some spherical viruses. Virology, 39, 294.

Bayer, M.E., Blumberg, B.S. \& Werner, B. (1968) Particles associated with Australia antigen in the sera of patients with leukaemia, Down's syndrome and hepatitis. Nature, 218, 1057.

Cossart, Y. \& Field, A. (1970) Virus-like particles in serum of patients with Australia-antigen-associated hepatitis. Lancet, i, 848.

Dane, D.S., Cameron, C.H. \& Briggs, M. (1970) Virus-like particles in serum of patients with Australia-antigenassociated hepatitis. Lancet, i, 695.

Gerin, J.L., Purcell, R.H., Hoggan, M.D., Holland, P.V. \& CHANOCK, R.M. (1969) Biophysical properties of Australia antigen. Journal of Virology, 4, 763.

Le Bouvier, G.L. \& McCollum, R.W. (1970) Australia (hepatitis associated) antigen. Physicochemical and immunological characteristics. Advances in Virus Research, 16, 357.

Millman, I., Zavotone, V., Gerstley, B.J.S. \& Blumberg, B.S. (1969) Australia antigen detected in the nuclei of liver cells of patients with viral hepatitis by the fluorescent antibody technique. Nature, 221, 181.

Nelson, J.M., Barker, L.F. \& Danovitch, S.H. (1970) Intranuclear aggregates in the liver of a patient with serum hepatitis. Lancet, ii, 773.

Nowoslawski, A., Brzosko, W.J., Madalinski, K. \& KRAWCZYNSKI, K. (1970) Cellular localisation of Australia antigen in the liver of patients with lymphoproliferative disorders. Lancet, i, 494.

Prince, A.M. (1968) An antigen detected in the blood during the incubation period of serum hepatitis. Proceedings of the National Academy of Sciences of the United States of America, 60, 814.

Shulman, N.R., Barker, L.F. (1969) Virus-like antigen, antibody, and antigen-antibody complexes in hepatitis measured by complement fixation. Science, 165, 304.

Trowell, J.M., Neale, G., Almeida, J.D. \& Waterson, A.P. (1971) In preparation. 